\title{
Chemical Composition and Efficacy of Lantana camara L. Essential Oil against Post harvest Invasion of Chickpea by Pulse Beetle (Callosobruchus chinensis L.)
}

\author{
Ashok Kumar* \\ Department of Botany, Dr. Bhimrao Ambedkar Government Degree College, \\ Maharajganj-273303, Uttar Pradesh, India \\ *Corresponding author
}

\section{A B S T R A C T}

Keywords

Lantana camara; Essential oil; Callosobruchus chinensis; Insecticidal; GCMS

Article Info

\section{Accepted:} 22 April 2021 Available Online: 10 May 2021
Pulse beetle (Callosobruchus chinensis L.) invasion results qualitative and quantitative losses of chickpea seeds during storage. Most of the synthetic chemicals used as preservative are having adverse effects. Therefore, insecticidal potential of Lantana camara L. essential oil (LcEO) was evaluated to find out an eco-friendly substitute of synthetic pesticides. The chemical profile of LcEO exhibited 31 known components. Germacrene-D (37.12\%) was found as major component followed by $\beta$-Caryophyllene $(25.18 \%)$ and Germacrene-B (16.35\%). LcEO oil showed potent insecticidal activity against C. chinensis at different concentrations and exposure time. The oviposition by C. chinensis was completely checked at $10 \mu \mathrm{L}^{-1}$ while $\mathrm{F}_{1}$ emergence was

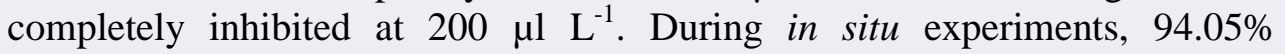
protection of the chickpea from $C$. chinensis by LcEO showed superiority over organophosphate insecticide malathion where $90.75 \%$ protection was recorded. The LcEO showing potent insecticidal efficacy and may be recommended as plant based preservative in the management of insect infestation of chickpea and other pulses during storage.

\section{Introduction}

Postharvest losses of food commodities in Indian subcontinent is a burning issue because $20-60 \%$ of stored grains are deteriorated by various pests viz. insects, fungi, bacteria, rodents etc. (Shaaya et al., 1997). Hot and humid climatic conditions of tropical region are most conducive for infestation of stored pulse commodities by insects especially bruchidaes (Shimizu and Hori, 2009). The pulse beetle, Callosobruchus has numerous species causes enormous damage to economically important legumes during 
storage in tropics (Shukla et al., 2007). To overcome such storage problems, an effective control measure have to develop which minimize the quantitative losses due to infestation by different insect pests.

The application of various prevalent synthetic pesticides since last few decades has made a significant contribution in management of such storage losses but has also raised adverse effects on environmental and human health (Rajkumar et al., 2019). Therefore, some safer alternatives of synthetic chemicals should be explored. Now days, some botanical products are explored as safer and eco-friendly alternative of various synthetic pesticides to protect stored crops and their products (Isman, 2006). Recently, essential oils (EOs) of various plant species are gaining attention because of their bioactivity as insecticidal (Upadhyay et al., 2019), antibacterial (Pandey et al., 2017), antifungal, antioxidant and bioregulatory properties (Holley and Patel, 2005). Therefore, in the present study, efficacy of Lantana camara L. (FamilyVerbenaceae) essential oil (LcEO) against pulse beetle Callosobruchus chinensis L. causing significant deterioration of chickpea (Cicer arietinum L.) has been explored to minimize postharvest invasion of pulses as well as enhancement of their shelf life.

\section{Materials and Methods}

\section{Sampling}

Chickpea seeds (variety- Radha) of about 4-6 months of storage were procured and collected in sterilized polythene bags to avoid further invasion.

\section{Isolation of $L$. camara leaf essential oil}

Leaves (500 g) of L. camara was thoroughly washed with water and subjected to Clevenger's hydro-distillation apparatus for extraction of EO. The extracted LcEO was dehydrated with anhydrous sodium sulphate and stored in dark clean glass vial at $4 \pm 2{ }^{\circ} \mathrm{C}$ (Kumar et al., 2013).

\section{GC-MS analysis of LcEO}

Chemical profile of LcEO was performed at Central Institute of Medicinal and Aromatic Plants, Lucknow, India. To determine chemical profile, LcEO was subjected to GCMS (Perkin Elmer Turbomass Gold MA, USA) using $60 \mathrm{~mm} \times 0.32 \mathrm{~mm} \times 0.25 \mathrm{~mm}$ capillary column.

The GC was performed with injection temperature $250^{\circ} \mathrm{C}$; detector temperature $270^{\circ} \mathrm{C}$; column temperature program isotherm at $70^{\circ} \mathrm{C}$ for $2 \mathrm{~min}, 3^{\circ} \mathrm{C} / \mathrm{min}$ gradient to $250^{\circ} \mathrm{C}$, isotherm duration was $10 \mathrm{~min}$ and flow rate of carrier gas (He) was $1 \mathrm{ml} / \mathrm{min}$. The components of LcEO were identified by comparing their retention times and mass spectra with authentic reference compounds in the literature available in mass spectral libraries of Wiley, NIST and NBS (Adams, 2007).

\section{Insect repellent activity of LcEO}

The insect repellency of LcEO was tested against $C$. chinensis following Upadhyay et al., (2019) using ' $\mathrm{Y}$ ' shaped Olfactometer. The repellency experiment was carried out at room temperature $\left(27 \pm 2^{\circ} \mathrm{C}\right)$. A cotton swab soaked separately with requisite amount of LcEO to find out the desired concentration viz. 10, 50, 100, 200 and $500 \mu \mathrm{l} / \mathrm{L}$ with respect to the aerial volume of Olfactometer was plugged in treatment arm whereas in control arm cotton swab without LcEO was plugged.

Thirty adult insects were inserted separately from the base of the Olfactometer. After 30 min the number of insects in the treatment and control arm was recorded. 


\section{Insecticidal activity of LcEO}

The insecticidal activity of LcEO against $C$. chinensis was assessed by direct contact method. The requisite amount of LcEO was soaked on two layered Whatman no. 1 filter paper placed in a Petri dish $(90 \mathrm{~mm})$ to find out the final concentrations i.e. $0.1,0.5,1,5$, $10,50,100$ and $200 \mu \mathrm{l} / \mathrm{L}$ as per aerial volume of Petri plate. Thirty insects of equal age (5-7 days) were inserted separately in Petri dishes fumigated with LcEO. Control sets were kept parallel to treatment sets without LcEO. Percent mortality of insects in each set was recorded on 2, 4, 6, 8 and 10 hour exposure (Kumar et al., 2009).

\section{Oviposition deterrent activity of LcEO}

The LcEO was tested for its effect on oviposition of $C$. chinensis. Healthy seeds (50 g) of chickpea were taken in plastic containers $(250 \mathrm{ml})$ and fumigated separately with requisite concentrations viz. 0.1, 0.5, 1.0, 2.0, 5.0 and $10.0 \mu \mathrm{l} / \mathrm{L}$ of LcEO.

After an hour, 30 bruchids of almost same age were introduced in each container separately for egg laying. The control sets run along with treatment set without LcEO. Insects were removed after 24 hours and laid eggs were counted after 3-4 day of release. The effect of LcEO in reduction of egg laying was calculated following Sabbour (2019).

\section{Ovicidal activity of LcEO}

The LcEO was tested for its inhibitory effect on $\mathrm{F}_{1}$ adult emergence of $C$. chinensis. Chickpea seeds containing eggs were taken in plastic containers $(250 \mathrm{ml})$ and fumigated separately with requisite concentrations viz. 5 , $10,20,50,100,200,500$ and $1000 \mu \mathrm{l} / \mathrm{L}$ of LcEO. The fumigated sets along with control were incubated at $27 \pm 2^{\circ} \mathrm{C}$ and $\mathrm{RH} 80 \pm 5 \%$. The number of pulse beetles of $F_{1}$ generation emerging from chickpea seeds from fumigated and control sets was recorded up to 30 days. The effect of LcEO on adult development $\left(\mathrm{F}_{1}\right.$ generation) was determined following Kumar et al., (2009).

\section{Determination of feeding deterrence index}

To determine its practical applicability, $5.0 \mathrm{~kg}$ of chickpea seeds were fumigated with $1.0 \mathrm{ml}$ LcEO in plastic containers $(10 \mathrm{~L})$ for six months. Along with treatment sets, one positive control fumigated with malathion, an organophosphate insecticide at $1.0 \mathrm{~g} / 10 \mathrm{~L}$ and one negative control without fumigation was also kept. All the containers were infested with $25.0 \mathrm{~g}$ of previously infested chickpea seeds. The level of insect infestation and grain damage was monitored after six months by quantifying the feeding deterrence index (Brari and Kumar, 2019).

\section{Seed germination test}

The percent germination of chickpea seeds, fumigated with LcEO, was tested after six month of storage. Hundred uninfested seeds were taken from each fumigated set, soaked in distilled water for $3 \mathrm{~h}$.

Thereafter, seeds were aseptically transferred to Petri dishes $(15 \mathrm{~cm}$ diameter) containing moist filter paper and incubated at $25 \pm 2^{\circ} \mathrm{C}$. Hundred healthy and uninfested seeds were procured from the market as control for comparison. The number of seeds germinated within a week was recorded as viable (Kumar et al., 2009).

\section{Data Analysis}

All the treatments were in triplicate and the data presented are mean \pm Standard Error (SE). The data for bioactivity of LcEO against $C$. chinensis were analysed using software SPSS version 16.0. 


\section{Results and Discussion}

The LcEO was extracted through hydrodistillation and characterized with its pungent smell, yellow green colour and 0.96 $\%$ yield $(\mathrm{w} / \mathrm{w})$. The GC/GC-MS analysis of LcEO showed 31 considerable peaks. The GC-MS analysis exhibited Germacrene-D (37.12\%) as major component followed by $\beta$ Caryophyllene $(25.18 \%)$ and Germacrene-B $(16.35 \%)$ were recorded as major components. $\beta$-Pinene (1.40\%), $\beta$-Caryophyllene (1.32\%), Caryophyllene oxide $(1.22 \%), \quad \beta$-Elemene (1.21\%), $\alpha$-Terpineol (1.19\%), Terpinene-4-ol $(1.10 \%)$, Viridiflorol $(1.06 \%), \quad \delta$-Cadinol $(1.03 \%)$ and Valencene $(1.10 \%)$ were recorded in small quantity while rest other identified components were found in trace amount (Table 1; Fig. 1).

The percent insect repellency of LcEO against C. chinensis increased with increasing concentration. The percent repellency increased upto $100 \mu \mathrm{l} / \mathrm{L}$ and beyond this became almost constant (Fig. 2).

Similarly, LcEO exhibited potent insecticidal activity which was found directly proportional to concentration and exposure period. During the study $100 \%$ mortality of the insect was recorded at $200 \mu \mathrm{l} / \mathrm{L}$ on two hour exposure to oil while complete mortality was noted at 1 $\mu \mathrm{l} / \mathrm{L}$ when exposure period was increased to 10 hour (Fig. 3).

In addition, oviposition deterrency and ovicidal activity of LcEO was also evaluated. LcEO altered the egg laying behavior of $C$. chinensis. The oviposition deterrency increased with increasing LcEO concentration and egg laying was completely checked at 10 $\mu \mathrm{l} / \mathrm{L}$ (Fig. 4). The LcEO potentially inhibited the adult emergence from the eggs. The $F_{1}$ emergence decreased with increasing EO concentration and completely checked at 200 $\mu 1 /$ L (Fig. 5).
During in situ experiments conducted to observe efficacy of LcEO as feeding deterrent, $89.46 \%$ protection of the chickpea from $C$. chinensis infestation was recorded showing slight superiority of LcEO over the prevalent organophosphate insecticide malathion where $88.63 \%$ protection was recorded (Table 2). The treated chickpea seeds having no significant losses in their viability even after six months of fumigation. LcEO treated chickpea seeds showed $73.52 \%$ germination while malathion exhibited $72.81 \%$ (Table 3) also showing minor superiority over malathion.

L. camara L. plants are luxuriously growing as weed is an invasive species found in most part of Uttar Pradesh (Kumar et al., 2010). The plant contains significant amount of EO, highly demanded in various industries. The chemical composition of EOs varies with age of the plant, season of collection, geographical area and soil characteristics (Rawat et al., 2020). Hence, the extracted LcEO was standardized to determine its chemical profile through GC-MS analysis. Plant EOs are complex mixtures of terpenic (especially mono- and sesquiterpenes and mono- and sesquiterpenoids), aromatic, and aliphatic components (Ebadollahi et al., 2020).

Plant EOs or their volatile components cause critical defense strategies against herbivorous pests. They also have a vigorous role in plantplant interactions and attraction of pollinators (Theis and Lerdau, 2003; Tholl, 2006). EOs exhibit a wide spectrum of pesticidal activities from lethal to sublethal effects against a wide range of insects and mites (Campos et al., 2019). Pesticidal effects of essential oils extracted from different plant families such as Apiaceae, Asteraceae, Chenopodiaceae, Cupressaceae, Lamiaceae, Lauraceae, Myrtaceae, Zingiberaceae, Umbelliferae, and Geraniaceae have been documented (Ebadollahi et al., 2020) 
Table.1 Chemical composition of LcEO

\begin{tabular}{|c|c|c|}
\hline RT & Compounds & Percentage \\
\hline 7.201 & 3-Methyl-2-heptanone & 0.18 \\
\hline 8.401 & 2-Methylcyclopentanol acetate & Tr* \\
\hline 10.476 & 2,6-Dimethyl-2,7-octadiene-1,6-diol & $\operatorname{Tr}^{*}$ \\
\hline 11.177 & 6-Methyl-5-hepten-2-one & 0.32 \\
\hline 11.301 & $\alpha$-Pinene & 0.73 \\
\hline 11.951 & Sabinene & Tr* \\
\hline 12.286 & Caryophyllene diepoxide & 0.57 \\
\hline 12.501 & Linalol oxide & 0.27 \\
\hline 12.901 & $\beta$-Pinene & 1.40 \\
\hline 13.226 & Terpinolene & 0.41 \\
\hline 13.401 & 2-Nonyne & 0.36 \\
\hline 14.351 & Terpinene-4-ol & 1.10 \\
\hline 14.751 & $\alpha$-Terpineol & 1.19 \\
\hline 14.926 & $\delta$-Elemene & 0.68 \\
\hline 15.922 & $\beta$-Caryophyllene & 25.18 \\
\hline 16.551 & $\alpha$-Copaene & 0.87 \\
\hline 17.126 & Linalyl acetate & Tr* \\
\hline 18.301 & $\beta$-Elemene & 1.21 \\
\hline 18.951 & $\beta$-Caryophyllene & 1.32 \\
\hline 19.451 & $\gamma$-Elemene & 0.77 \\
\hline 20.134 & Germacrene-D & 37.12 \\
\hline 26.526 & Valencene & 0.68 \\
\hline 24.676 & Trans carvone oxide & 1.01 \\
\hline 28.776 & Germacrene-B & 16.35 \\
\hline 31.401 & 3-Heptadecen-5-yne & Tr* \\
\hline 38.276 & Caryophyllene oxide & 1.22 \\
\hline 44.224 & 2,3,4,5-Tetramethyl cyclopent-2-en-1-ol & Tr* \\
\hline 48.217 & $\beta$-Costal & 0.69 \\
\hline 51.202 & Viridiflorol & 0.36 \\
\hline 54.652 & $\alpha$-Farnesene & 0.38 \\
\hline \multirow[t]{2}{*}{55.727} & $\delta$-Cadinol & 1.03 \\
\hline & Total & 95.\% \\
\hline
\end{tabular}

RT= Retention time; Tr*- Trace amount $(<0.10 \%)$

Table.2 Comparative efficacy of LcEO and malathion on feeding behaviour of $C$. chinensis

\begin{tabular}{|c|c|c|}
\hline Fumigants & Dose & FDI (\%) \\
\hline LcEO & $100 \mu \mathrm{L} \mathrm{L}^{-1}$ & $89.46 \pm 4.18$ \\
\hline Malathion & $100 \mathrm{mg} \mathrm{L}^{-1}$ & $88.63 \pm 3.28$ \\
\hline
\end{tabular}

Values are mean $(n=3) \pm$ standard error 
Table.3 Comparative efficacy of LcEO and malathion on germination of chickpea seeds

\begin{tabular}{|c|c|}
\hline Treatment & Germination (\%) \\
\hline Control & $\mathbf{8 4 . 7 2} \pm \mathbf{4 . 1 4}$ \\
\hline LcEO & $\mathbf{7 3 . 5 2} \pm \mathbf{5 . 2 6}$ \\
\hline Malathion & $\mathbf{7 2 . 8 1} \pm \mathbf{3 . 4 2}$ \\
\hline
\end{tabular}

Values are mean $(\mathrm{n}=3) \pm$ standard error

Fig.1 GC-MS chromatogram of LcEO

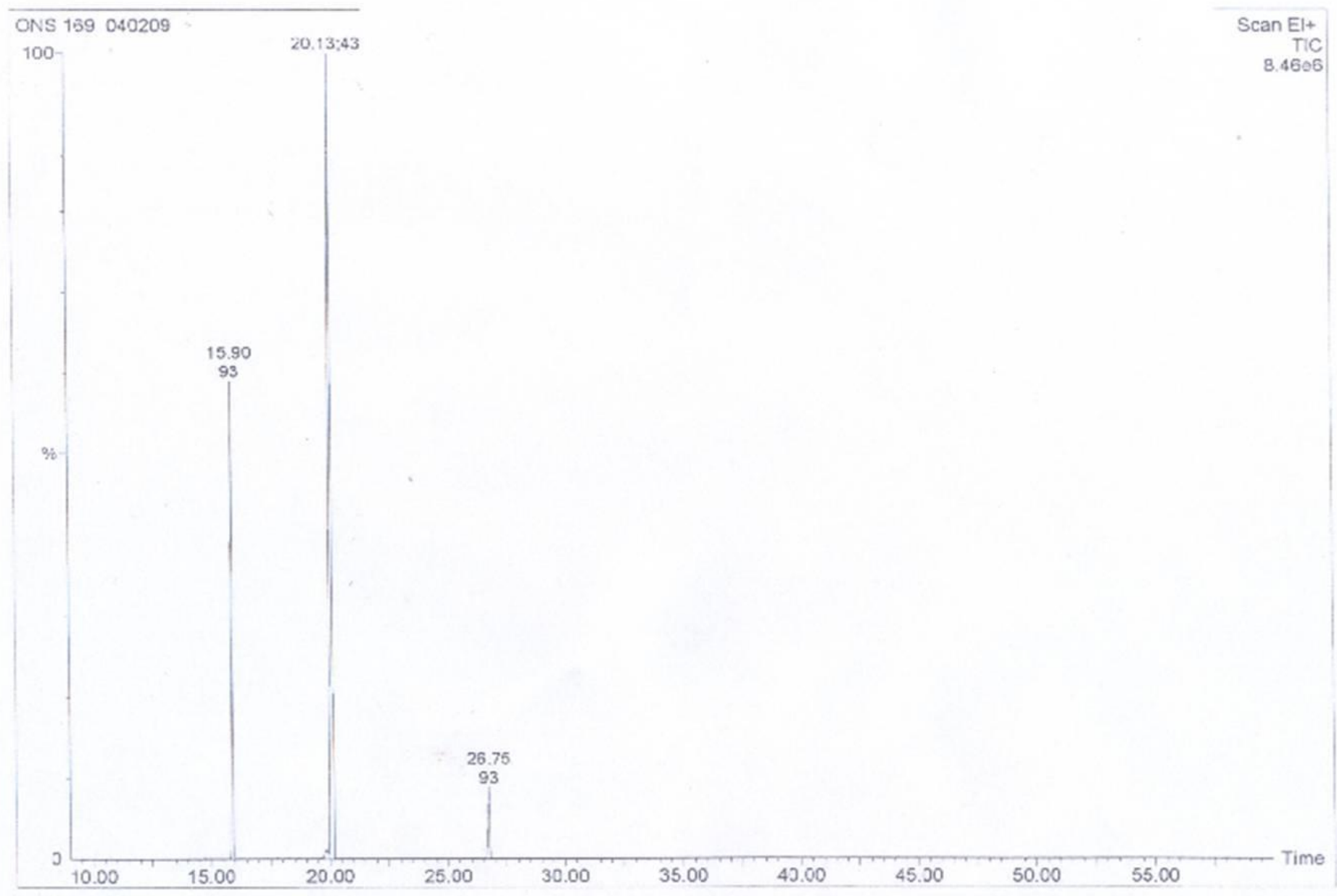


Fig.2 Insect repellent activity of LcEO against $C$. chinensis

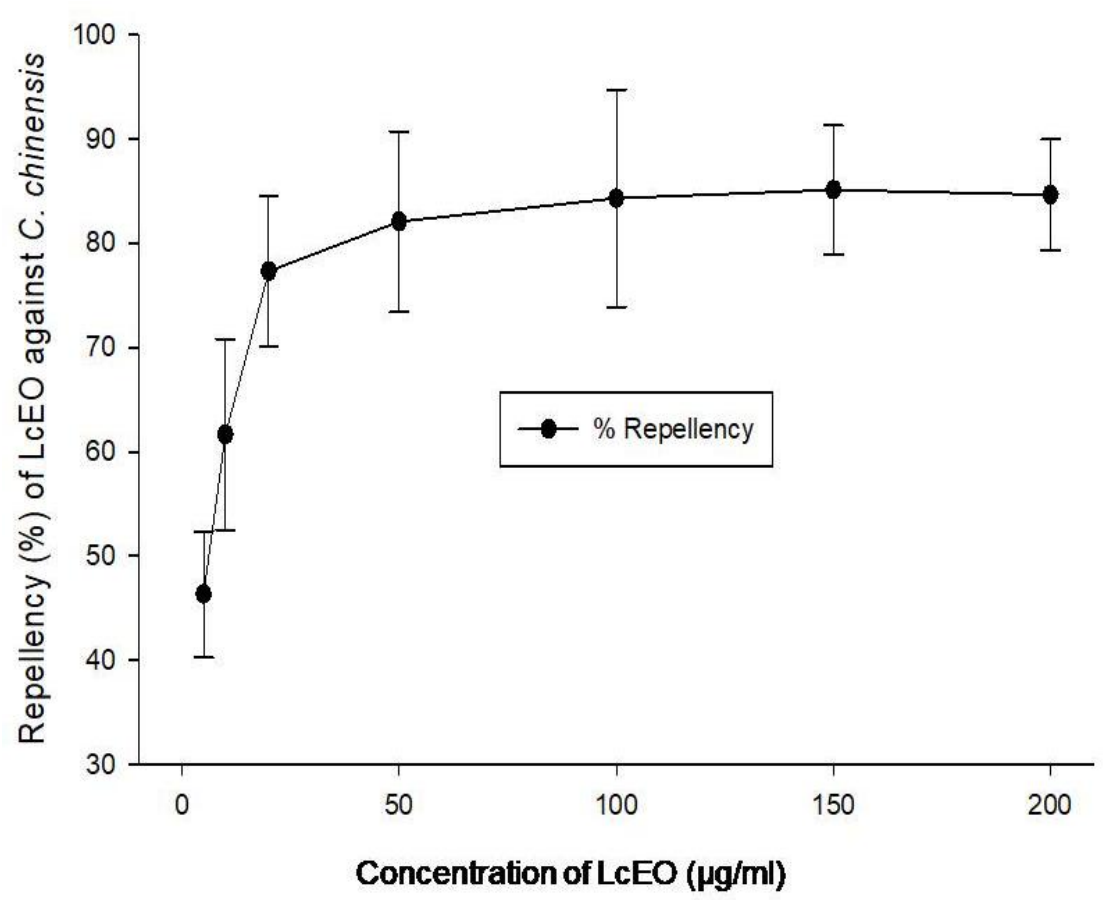

Fig.3 Oviposition deterrent activity of LcEO against egg laying of $C$. chinensis

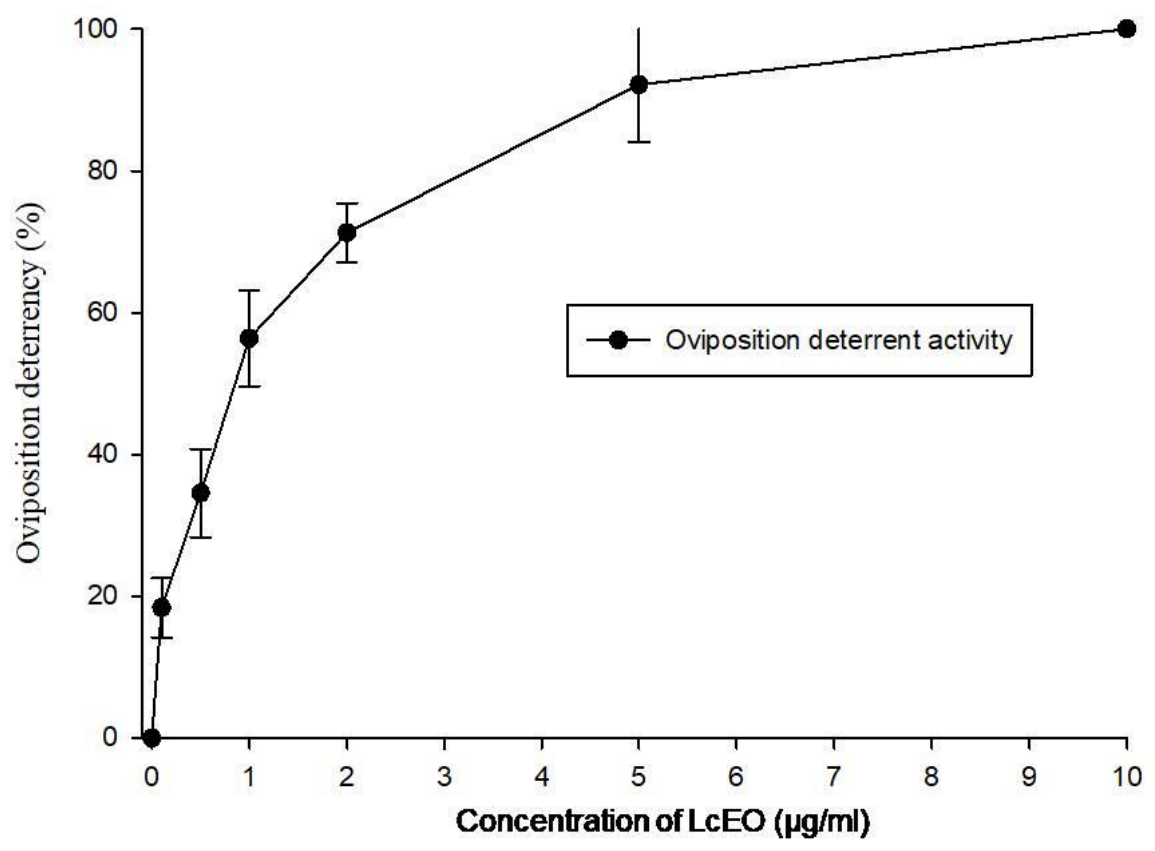


Fig.4 Ovicidal activity of LcEO against $C$. chinensis

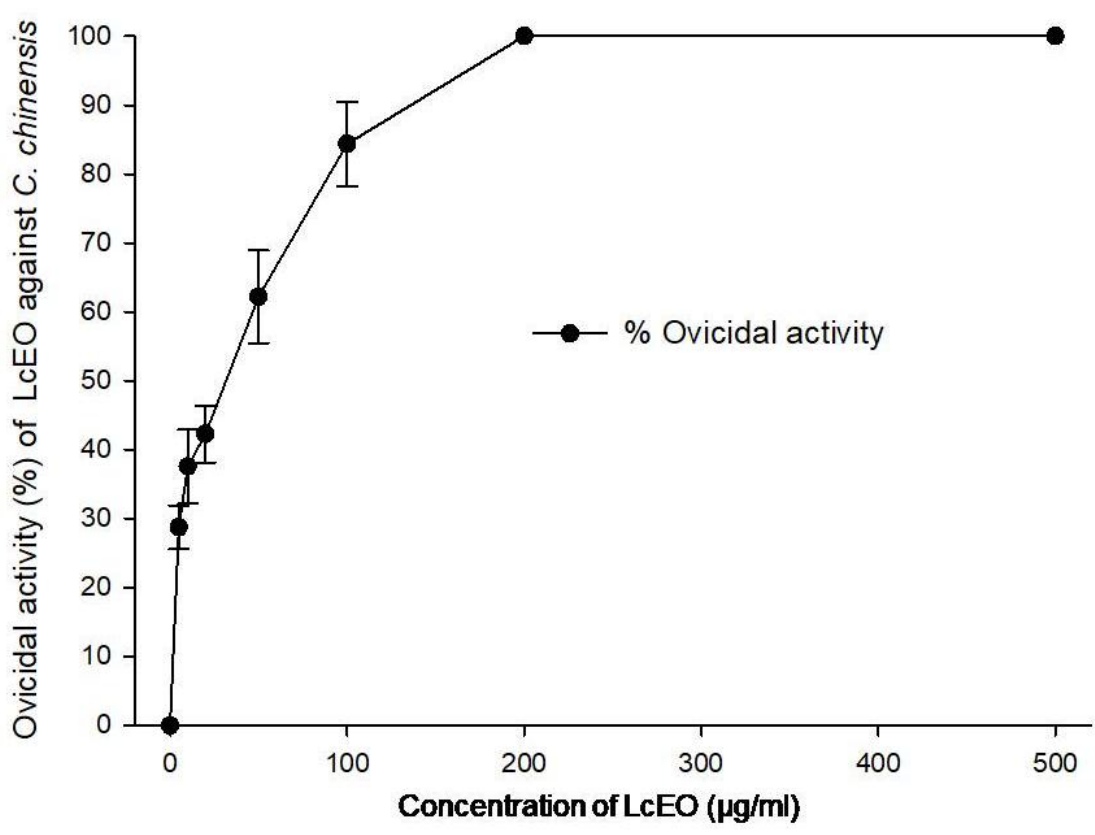

Fig.5 Insecticidal activity (\%) of LcEO against $C$. chinensis

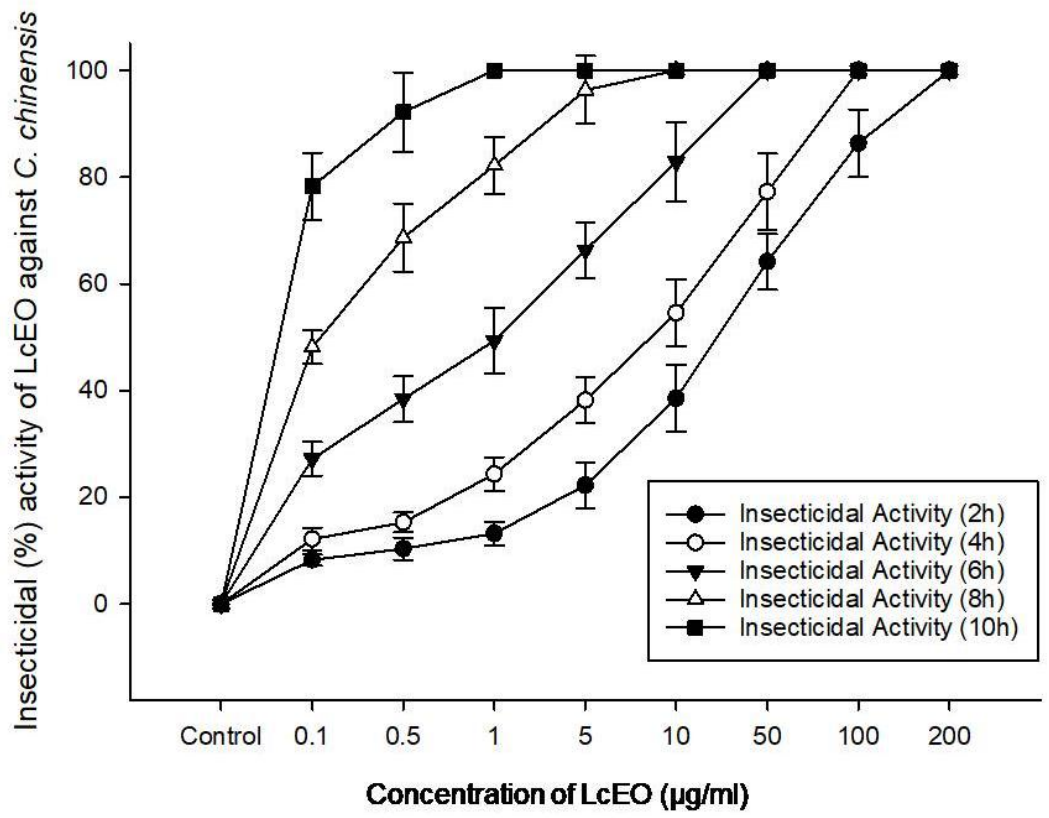

In the present investigation, an effort has been made to evaluate the efficacy of LcEO against pulse beetle $C$. chinensis severely infested stored chickpea seeds. Although, some plant products like azadirachtin (Chaudhary et al., 2017), pyrethrum (Sun et al., 2020), rotenone
(Huang et al., 2018), sabadilla (Isman, 2006), ryania (Jefferies et al., 1992), termeron (Leyva et al., 2020) etc. are in large scale use in control of different insect pests. The LcEO in the present investigation showed potent insecticidal efficacy. Such a virtue of LcEO 
would increase its market value if formulated as botanical pesticide in protection of stored food commodities.

The degree of susceptibility of $C$. chinensis adults to LcEO varies with concentration and exposure period. By increasing the exposure duration $(10 \mathrm{hr})$, the oil showed complete mortality of the insects even at $1 \mu \mathrm{l} / \mathrm{L}$.

Thus, even lower doses of the LcEO may be sufficient to protect the commodities from insect infestation in case of their storage for longer duration. Similarly, oviposition deterrency is also directly related with LcEO concentration.

The volatiles present in the LcEO may be altering the egg laying behaviour of the insects as reported by Autran et al., (2009). Such products in pest management are termed as 'behavior altering chemicals or "semiochemicals" and are recommended in integrated pest management. The use of such 'behavior altering chemicals' would solve the problem of resistance development in target pests which is frequently reported by use of different prevalent synthetic chemicals which act through cidal (lethal) mode of action (Isman, 2006). Likewise, the reduction in $F_{1}$ emergence from the treated eggs may be due to mortality of developing embryos in the eggs exposed to the LcEO.

The findings of the present investigation may draw the attention regarding large scale exploitation of LcEO as plant based insecticide for stored food commodities. The attraction of modern society towards 'green consumerism' (Smid and Gorris, 1999) desiring fewer synthetic chemicals in protection of food commodities and recommendation of herbal products as 'generally recognized as safe' (GRAS) in the developed countries (Burt, 2004). The significant bioactivity of LcEO against pulse beetle may lead scientific interest for its exploitation in postharvest storage technology of food commodities in complete protection from insect pests. The LcEO may be a safer alternative to prevalent insecticides in control of postharvest insect invasion of food commodities and pulses. Because of luxuriant growth of $L$. camara in central India, sufficient amount of raw materials would be available for the extraction of EO. Further investigations are needed to determine its safety profile and the exact mode of action of the active ingredients.

The findings of present investigation reveal that, the LcEO exhibited strong insect repellent, insecticidal, oviposition deterrent and ovicidal activity against pulse beetle $C$. chinensis strengthen its possible exploitation as an indigenous, safe plant-based green pesticide for postharvest storage of food commodities to enhance their shelf life against insect pests.

\section{Acknowledgement}

Author is grateful to Prof. N. K. Dubey, Head, Centre of Advanced Study (CAS) in Botany, Institute of Science, Banaras Hindu University, Varanasi for providing laboratory facilities and Director, Central Institute of Medicinal and Aromatic Plants (CIMAP), Lucknow for chemical characterization of LcEO.

\section{References}

Adams, R. P., 2007. Identification of essential oil components by Gas Chromatography/Mass Spectrometry. Allured Publishing Corporation, Carol Stream, IL.

Autran, E. S., Neves, I. A., Da Silva, C. S. B., Santos, G. K. N., Da Câmara, C. A. G. and Navarro, D. M. A. F. 2009. Chemical composition, oviposition deterrent and larvicidal activities 
against Aedes aegypti of essential oils from Piper marginatum Jacq. (Piperaceae). Biores. Technol. 100: 2284-2288.

Brari, J. and Kumar, V. 2019. Antifeedant activity of four plant essential oils against major stored product insect pests. Int. J. Pure Appl. Zool. 7(3): 4145.

Burt, S. 2004. Essential oils: their antibacterial properties and potential applications in foods-a review. Int. J. Food Microbiol. 94: 223-253.

Campos, E. V. R., Proença, P. L. F., Oliveira, J. L., Bakshi, M., Abhilash, P. C. and Fraceto, L. F. 2019. Use of botanical insecticides for sustainable agriculture: Future perspectives. Ecol. Indic. 105: 483-495.

Chaudhary, S., Kanwar, R. K., Sehgal, A., Cahill, D. M., Barrow, C. J., Sehgal, R. and Kanwar, J. R. 2017. Progress on Azadirachta indica based biopesticides in replacing synthetic toxic pesticides. Front. Plant Sci. 8:610. Doi: 10.3389/fpls.2017.00610.

Ebadollahi, A., Ziaee, M., and Palla, F. 2020. Essential oils extracted from different species of the lamiaceae plant family as prospective bioagents against several detrimental pests. Molecules. 25:1556.

Doi: 10.3390/molecules25071556.

Holley, R. A. and Patel, D. 2005. Improvement in shelf-life and safety of perishable foods by plant essential oils and smoke antimicrobials. Food Microbiol. 22: 273-292.

Huang, C. W., Lin, K. M., Hung, T. Y., Chuang, Y. C. and Wu, S. N. 2018. Multiple actions of rotenone, an inhibitor of mitochondrial respiratory chain, on ionic currents and miniature end plate potential in mouse Hippocampal (mhippoe-14) neurons. Cell. Physiol. Biochem. 47: 330-343.
Isman, M. B. 2006. Botanical insecticides, deterrents, and repellents in modern agriculture and an increasingly regulated world. Ann. Rev. Entomol. 51: 45-66.

Jefferies, P. R., Toia, R. F., Brannigan, B., Pessah, I. and Casida, J.E. 1992. Ryania insecticide: analysis and biological activity of 10 natural ryanoids. J. Agric. Food Chem. 40: 142-146.

Kumar, A., Dubey, N. K. and Srivastava, S. 2013. Antifungal evaluation of Ocimum sanctum essential oil against fungal deterioration of raw materials of Rauvolfia serpentina during storage. Ind. Crop. Prod. 45: 30-35.

Kumar, A., Shukla, R., Singh, P., Anuradha, and Dubey, N. K. 2010. Efficacy of extract and essential oil of Lantana indica Roxb. against food contaminating moulds and aflatoxin B1 production. Int. J. Food Sci. Technol. 45: 179-185.

Kumar, A., Shukla, R., Singh, P., Singh, A. K., and Dubey, N. K. 2009. Use of essential oil from Mentha arvensis L. to control storage moulds and insects in stored chickpea. J. Sci. Food Agric. 89: 2643-2649.

Leyva, C. S., Sánchez, D. O. S., Chora, G. P., Loyo, A. G. T., Cortázar, M. G. and Zamilpa, A. 2020. Insecticidal compounds in Ricinus communis L. (Euphorbiaceae) to control Melanaphis sacchari Zehntner (Hemiptera: Aphididae). Fla. Entomol. 103(1): 9195.

Pandey, A. K., Kumar, P., Singh, P., Tripathi, N. N. and Bajpai, V. K. 2017. Essential oils: Sources of antimicrobials and food preservatives. Front. Microbiol. 7: 2161. https://doi.org/10.3389/fmicb.2016.021 61.

Rajkumar, V., Gunasekaran, C., Christy, I. K., 
Dharmaraj, J., Chinnaraj, P. and Paul. C.A. 2019. Toxicity, antifeedant and biochemical efficacy of Mentha piperita L. essential oil and their major constituents against stored grain pest. Pest. Biochem. Physiol. 156: 138-144.

Sabbour, M. M. A. 2019. Efficacy of natural oils against the biological activity on Callosobruchus maculatus and Callosobruchus chinensis (Coleoptera: Tenebrionidae). Bull. Natl. Res. Cent. 43: 206.

Shaaya, E., Kostjukovski, M., Eilberg, J. and Sukprakarn, C. 1997. Plant oils as fumigants and contact insecticides for the control of stored product insects. J. Stored Prod. Res. 33:7-15.

Shimizu, C. and Hori, M. 2009. Repellency and toxicity of troponoid compounds against the adzuki bean beetle, Callosobruchus chinensis (L.) (Coleoptera: Bruchidae). J. Stored Prod. Res. 45: 49-53.

Shukla, R., Srivastava, B., Kumar, R. and Dubey, N. K. 2007. Potential of some botanical powders in reducing infestation of chickpea by Callosobruchus chinensis L.
(Coleoptera : Bruchidae). J. Agric. Technol. 3: 11-19.

Smid, E. J. and Gorris, L. G. M. 1999. Natural antimicrobials for food preservation, in Handbook of food preservation, ed. by Rahman M. S. Marcel Dekker, New York, pp. 285-308.

Sun, W., Shahrajabian, M. H. and Cheng, Q. 2020. Pyrethrum an organic and natural pesticide. J. Biol. Environ. Sci. 14(40): 41-44.

Theis, N., and Lerdau, M. 2003. The evolution of function in plant secondary metabolites. Int. J. Plant Sci. 164: 93102.

Tholl, D. 2006. Terpene synthases and the regulation, diversity and biological roles of terpene metabolism. Curr. Opin. Plant Biol. 9: 297-304.

Upadhyay, N., Singh, V. K., Dwivedy, A. K., Das, S., Chaudhari, A. K. and Dubey, N.K. 2019. Assessment of Melissa officinalis L. essential oil as an ecofriendly approach against biodeterioration of wheat flour caused by Tribolium castaneum Herbst. Environ. Sci. Pollut. Res. 26: 1403614049.

\section{How to cite this article:}

Ashok Kumar. 2021. Chemical Composition and Efficacy of Lantana camara L. Essential Oil against Post harvest Invasion of Chickpea by Pulse Beetle (Callosobruchus chinensis L.). Int.J.Curr.Microbiol.App.Sci. 10(05): 719-729. doi: https://doi.org/10.20546/ijcmas.2021.1005.081 